\title{
Soluble CD40 Ligand in Acute Coronary Syndromes
}

\author{
Christopher Heeschen, M.D., Stefanie Dimmeler, Ph.D., \\ Christian W. Hamm, M.D., Marcel J. van den Brand, M.D., \\ Eric Boersma, Ph.D., Andreas M. Zeiher, M.D., and Maarten L. Simoons, M.D., \\ for the CAPTURE Study Investigators
}

ABSTRACT

From the C7E3 Fab Antiplatelet Therapy in Unstable Refractory Angina (CAPTURE) Study (C.H., S.D., C.W.H., M.J.B., E.B., A.M.Z., M.L.S.); Molecular Cardiology, Department of Internal Medicine IV, University of Frankfurt, Frankfurt, Germany (C.H., S.D., A.M.Z.) the Kerckhoff Heart Center, Bad Nauheim Germany (C.W.H.); and the Thoraxcentre, Erasmus University, Rotterdam, the Netherlands (M.J.B., E.B., M.L.S.). Address reprint requests to Dr. Heeschen at the Department of Molecular Cardiology, Interna Medicine IV, University of Frankfurt, Theodor-Stern-Kai 7, 60590 Frankfurt, Germany, or at c.heeschen@em.uni-frankfurt.de.

N EnglJ Med 2003;348:1104-11.

Copyright $\odot 2003$ Massachusetts Medical Society.

\section{BACK GROUN D}

CD40 ligand is expressed on platelets and released from them on activation. We investigated the predictive value of soluble CD40 ligand as a marker for clinical outcome and the therapeutic effect of glycoprotein IIb/IIIa receptor inhibition in patients with acute coronary syndromes.

\section{METHODS}

Serum levels of soluble CD40 ligand were measured in 1088 patients with acute coronary syndromes who had previously been enrolled in a randomized trial comparing abciximab with placebo before coronary angioplasty and in 626 patients with acute chest pain.

\section{RESULTS}

The levels of soluble CD40 ligand were elevated (above $5.0 \mu \mathrm{g}$ per liter) in 221 patients with acute coronary syndromes (40.6 percent). Among patients receiving placebo, elevated soluble CD40 ligand levels indicated a significantly increased risk of death or nonfatal myocardial infarction during six months of follow-up (adjusted hazard ratio as compared with patients with low levels of the ligand [ $\leq 5.0 \mu$ g per liter], 2.71; 95 percent confidence interval, 1.51 to $5.35 ; \mathrm{P}=0.001$ ). The prognostic value of this marker was validated in the patients with chest pain, among whom elevated soluble CD40 ligand levels identified those with acute coronary syndromes who were at high risk for death or nonfatal myocardial infarction (adjusted hazard ratio as compared with those with low levels of the ligand, 6.65; 95 percent confidence interval, 3.18 to $13.89 ; \mathrm{P}<0.001)$. The increased risk in patients with elevated soluble CD40 ligand levels was significantly reduced by treatment with abciximab (adjusted hazard ratio as compared with those receiving placebo, $0.37 ; 95$ percent confidence interval, 0.20 to $0.68 ; \mathrm{P}=0.001$ ), whereas there was no significant treatment effect of abciximab in patients with low levels of soluble CD40 ligand.

\section{CONCLUSIONS}

In patients with unstable coronary artery disease, elevation of soluble CD40 ligand levels indicated an increased risk of cardiovascular events. Elevation of soluble CD40 ligand identifies a subgroup of patients at high risk who are likely to benefit from antiplatelet treatment with abciximab. 


\section{$\mathrm{E}$} STABLISHING THE CORRECT DIAGNOsis and initiating the appropriate treatment in patients with acute coronary syndromes who do not have ST-segment elevation can be challenging. Sensitive and specific markers of myocardial-cell necrosis, notably cardiac troponins, have become valuable tools in the evaluation of patients with acute coronary syndromes. ${ }^{1}$ However, troponins are not actively involved in the pathophysiology of acute coronary syndromes and, instead, represent a surrogate marker for the formation of fragile thrombi. ${ }^{2-4}$ Markers of platelet activation that can be used to identify disease activity even before myocardial necrosis occurs may provide important supplementary information for the diagnostic and therapeutic stratification of patients with acute coronary syndromes.

Increasing evidence suggests that CD40 ligand plays an important part in disease progression and plaque destabilization. ${ }^{5,6}$ The CD40-CD40 ligand system is widely distributed on a variety of leukocytic and nonleukocytic cells, including endothelial and smooth-muscle cells, ${ }^{7}$ and on activated platelets. ${ }^{8} \mathrm{CD} 40$ ligand also occurs in a soluble form that is fully active biologically, termed soluble CD40 ligand, ${ }^{9}$ which is shed from stimulated lymphocytes and is actively released after platelet stimulation. ${ }^{10,11}$ Soluble CD40 ligand is proinflammatory for endothelial cells and promotes coagulation by inducing expression of tissue factor on monocytes ${ }^{12}$ and endothelial cells. ${ }^{13}$ Moreover, soluble CD40 ligand contains a KGD sequence, ${ }^{9}$ a known binding motif that is specific for the major platelet integrin $\alpha \operatorname{IIb} \beta 3 .{ }^{14}$ Indeed, CD40 ligand has been demonstrated to be an $\alpha \operatorname{IIb} \beta 3$ (glycoprotein IIb/IIIa) ligand and a platelet agonist and to be necessary for the stability of arterial thrombi. ${ }^{15}$

These data suggest that soluble CD40 ligand plays an important part in the pathophysiology of acute coronary syndromes. Apparently healthy women with increased plasma levels of soluble CD40 ligand have been shown to be at increased risk for cardiovascular events. ${ }^{16}$ Elevation of soluble CD40 ligand levels is detectable in the serum of patients with acute coronary syndromes. ${ }^{17}$ Accordingly, we investigated the predictive value of serum levels of soluble CD40 ligand with respect to cardiac events and the effects of the glycoprotein IIb/IIIa inhibitor abciximab in patients with acute coronary syndromes who were enrolled in the c7E3 Fab Antiplatelet Therapy in Unstable Refractory Angina (CAPTURE) study. ${ }^{18}$

\section{METHODS}

\section{PATIENTS WITH ACUTE CORONARY SYNDROMES}

The CAPTURE trial enrolled 1265 patients with acute coronary syndromes who had recurrent chest pain at rest in association with electrocardiographic changes. Before randomization, all patients were documented by coronary angiography to have substantial coronary artery disease, with stenosis of at least 70 percent of the coronary-artery diameter at a culprit lesion that was suitable for angioplasty. The patients were randomly assigned to receive abciximab or placebo, and coronary angioplasty was scheduled 18 to 24 hours after the study treatment was begun. The combined primary end point was death or nonfatal myocardial infarction during 30 days and 6 months of follow-up. ${ }^{18}$

\section{PATIENTS With ACUte CHest Pain}

A separate validation sample consisted of 626 consecutive patients (465 men and 161 women; mean [ \pm SD] age, $62 \pm 12$ years) who presented with acute chest pain lasting less than 12 hours (mean, $5.1 \pm 3.6$ ) and had no ST-segment elevation on electrocardiography. The presence of coronary artery disease was documented by one of the following criteria: electrocardiographic evidence of myocardial ischemia (new ST-segment changes or T-wave inversions) or a history of coronary heart disease (myocardial infarction, coronary revascularization, a positive exercise stress test, or stenosis of more than 50 percent of the luminal diameter of a major coronary artery on a previous angiogram). All patients were followed for 30 days for the occurrence of death or nonfatal myocardial infarction. The study protocol was approved by the ethics committee of the Hamburg Medical Board, and written informed consent was obtained from each patient.

\section{BIOCHEMICAL ANALYSIS}

Soluble CD40 ligand, soluble P-selectin, high-sensitivity tumor necrosis factor $\alpha$, and soluble intracellular adhesion molecule 1 were measured by enzyme-linked immunosorbent assay (R\&D Systems). Troponin T was measured with an electrochemiluminescence enzyme-linked immunosorbent assay (Elecsys 2010, Roche Diagnostics), and C-reactive protein was measured by nephelometry (Behring BN II Nephelometer, Dade-Behring).

\section{IN VIVO PLATELET ACTIVATION}

In a subgroup of 161 patients with chest pain (131 patients with acute coronary syndromes, 20 patients 
with stable coronary heart disease, and 10 patients without coronary heart disease), platelet activation was assessed by flow cytometry with the use of phycoerythrin-conjugated glycoprotein IIb-specific monoclonal antibodies (CD41, Dako) and fluorescein isothiocyanate (FITC)-conjugated, P-selectinspecific monoclonal antibodies (BD Pharmingen). Circulating monocyte-platelet aggregates were stained with FITC-conjugated, glycoprotein IIIaspecific monoclonal antibody (CD61, Dako) and phycoerythrin-conjugated monoclonal antibodies against CD14 (BD Pharmingen). Monocyte-platelet aggregates were defined as monocytes positive for glycoprotein IIIa, and values are expressed as the percentage of aggregated monocytes. ${ }^{19}$

\section{STATISTICAL ANALYSIS}

To distinguish between patients with different degrees of cardiac risk, an exploratory data analysis was chosen. The Cox proportional-hazards regression model was used to estimate the relative risk of cardiovascular events, and patients were categorized according to quintiles of soluble CD40 ligand levels. ${ }^{20}$ We analyzed the effect of base-line characteristics and other biochemical markers on any observed associations between soluble CD40 ligand levels and cardiovascular events, using stepwise Cox

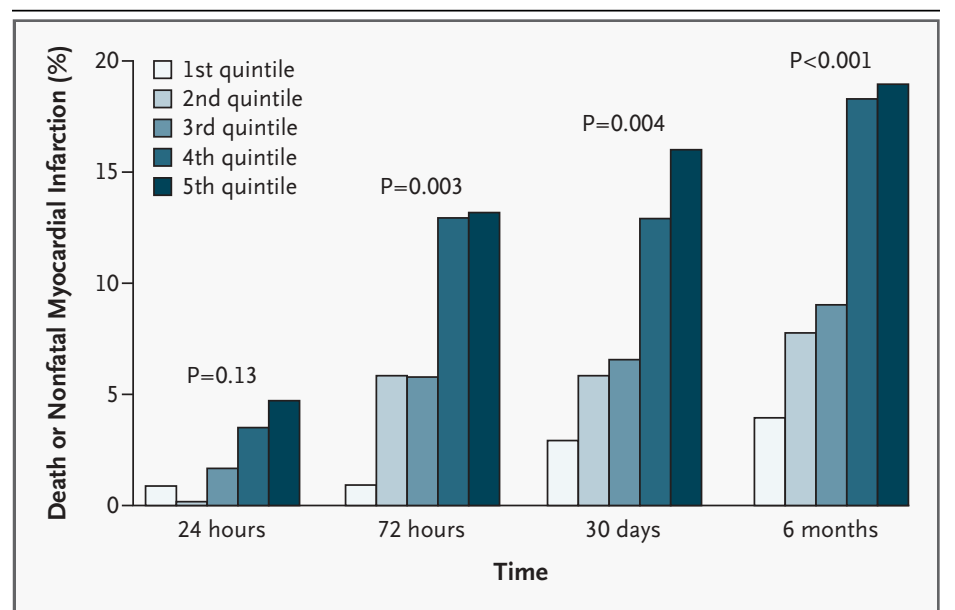

Figure 1. Association between Soluble CD40 Ligand Levels and the Rate of Cardiac Events (Death or Nonfatal Myocardial Infarction) at 24 Hours, 72 Hours, 30 Days, and 6 Months among 544 Patients Receiving Placebo.

The patients were divided into quintiles according to the serum level of soluble CD40 ligand, as follows: first quintile, below $1.93 \mu \mathrm{g}$ per liter; second quintile, 1.93 to $3.50 \mu \mathrm{g}$ per liter; third quintile, 3.51 to $5.00 \mu \mathrm{g}$ per liter; fourth quintile, 5.01 to $6.30 \mu \mathrm{g}$ per liter; and fifth quintile, above $6.30 \mu \mathrm{g}$ per liter. $\mathrm{P}$ values are for trend at each time point. proportional-hazards models (with a value of $\mathrm{P}=0.10$ necessary to enter a variable into the model). All results for continuous variables are expressed as means $\pm S D$. Comparisons between groups were analyzed with a two-sided t-test. Categorical variables were compared by the Pearson chi-square test. Post hoc analysis was performed by using the Cox proportional-hazards regression model, with the quintile for soluble CD40 ligand as a categorical variable and the quintile group with the lowest levels of soluble CD40 ligand serving as the reference group. P values under 0.05 were considered to indicate statistical significance. All analyses were performed with SPSS software (version 11.0).

\section{RES U LTS}

PATIENTS WITH ACUTE CORONARY SYNDROMES

Base-line samples were available for 1088 of the 1265 patients with acute coronary syndromes (86 percent). ${ }^{21}$ The level of soluble CD40 ligand did not correlate with measured levels of troponin $\mathrm{T}$ $(r=0.14)$ or $C$-reactive protein $(r=0.11)$.

\section{Soluble CD40 Ligand and Cardiovascular Risk}

The 544 patients in the placebo group of the study were classified according to their measured levels of soluble CD40 ligand at base line, as follows: 100 in the first quintile ( $<1.93 \mu \mathrm{g}$ per liter), 102 in the second quintile (1.93 to $3.50 \mu \mathrm{g}$ per liter), 121 in the third quintile (3.51 to $5.00 \mu \mathrm{g}$ per liter), 115 in the fourth quintile (5.01 to $6.30 \mu \mathrm{g}$ per liter), and 106 in the fifth quintile ( $>6.30 \mu \mathrm{g}$ per liter). For the initial 24-hour period before coronary angioplasty, the incidence of the combined end point of death or nonfatal myocardial infarction did not differ significantly among patients in these groups $(\mathrm{P}=0.13)$. For the later follow-up times ( 72 hours, 30 days, and 6 months), the rates of events were significantly higher in both the fourth quintile $(\mathrm{P}=0.01, \mathrm{P}=0.02$, and $\mathrm{P}=0.003$, respectively) and the fifth quintile $(\mathrm{P}=$ $0.009, \mathrm{P}=0.005$, and $\mathrm{P}=0.002$, respectively) (Fig. 1).

Accordingly, the patient sample was divided into two groups with soluble CD40 ligand levels of greater than $5.0 \mu \mathrm{g}$ per liter or $5.0 \mu \mathrm{g}$ per liter or less; 221 patients (40.6 percent) were thus classified as having high levels of soluble CD40 ligand and 323 patients as having low levels. There were no significant differences in the base-line characteristics of the two groups (Table 1 ). The incidence of death or nonfatal myocardial infarction was higher in patients who had elevated soluble CD40 ligand levels 
before coronary angioplasty (4.1 percent, vs. 0.9 percent among patients with low levels; $\mathrm{P}=0.02$ ), after 72 hours, a period during which coronary angioplasty was performed in all patients (13.1 percent vs. 4.3 percent, $\mathrm{P}<0.001$ ), after 30 days ( 14.5 percent vs. 5.3 percent, $\mathrm{P}<0.001)$, and after 6 months (18.6 percent vs. 7.1 percent, $\mathrm{P}<0.001$ ) (Fig. 2 and 3). The predictive value of soluble CD40 ligand was independent of the presence or absence of myocardial necrosis as evidenced by the troponin $\mathrm{T}$ level (Table 2). Among the patients who were negative for troponin T, high levels of soluble CD40 ligand identified a subgroup with an increased risk of cardiac events (13.6 percent) that was not significantly different from the risk in troponin $\mathrm{T}$-positive patients (14.0 percent, $\mathrm{P}=1.00$ ).

\section{Abciximab Treatment and Soluble CD40 Ligand}

Among patients in the first three quintiles for soluble CD40 ligand, no significant differences in cardiac risk were observed between those receiving placebo and those receiving abciximab (Fig. 4). Among patients in the highest two quintiles, a significant reduction in cardiac risk, which did not differ between the two quintiles, was documented for those receiving abciximab. The abrupt change in the hazard ratio from 1.12 in the third quintile to 0.35 in the fourth suggests a threshold level of benefit in this range of soluble CD40 ligand levels. Accordingly, curves for the incidence of death or nonfatal myocardial infarction were generated with a threshold level of $5.0 \mu \mathrm{g}$ of soluble CD40 per liter. Among patients with low levels of soluble CD40 ligand, no significant difference in incidence was observed between patients receiving abciximab and those receiving placebo (1.2 percent vs. 0.9 percent at 24 hours, and 3.8 percent vs. 4.3 percent at 72 hours) (Fig. 2). In contrast, the rates of death or nonfatal myocardial infarction were significantly higher among patients with high levels of soluble CD40 ligand who were receiving placebo and were effectively reduced by treatment with abciximab before coronary angioplasty (hazard ratio, 0.12; 95 percent confidence interval, 0.01 to $0.92 ; \mathrm{P}=0.01$ ); the same was true for angioplasty-related events (hazard ratio, 0.19; 95 percent confidence interval, 0.08 to 0.49 ; $\mathrm{P}<0.001$ ). This benefit persisted during six months of followup (hazard ratio, 0.37; 95 percent confidence interval, 0.20 to $0.68 ; \mathrm{P}=0.001$ ) (Fig. 3). Among troponin T-negative patients, high levels of soluble CD40 ligand identified a subgroup whose risk of cardiac events was significantly reduced by treatment with

\begin{tabular}{|c|c|c|c|}
\hline Characteristic & $\begin{array}{c}\text { Low } \\
\text { ( } \leq 5.0 \mu \mathrm{g} \text { per liter) }\end{array}$ & $\begin{array}{c}\text { High } \\
(>5.0 \mu \mathrm{g} \text { per liter })\end{array}$ & $P$ Value \\
\hline No. of patients & 323 & 221 & \\
\hline Male sex (\%) & 73.3 & 70.2 & 0.49 \\
\hline Mean age (yr) & $60.5 \pm 9.9$ & $62.3 \pm 10.5$ & 0.72 \\
\hline \multicolumn{4}{|l|}{ Clinical history (\%) } \\
\hline Angina $>7$ days previously & 57.5 & 54.6 & 0.59 \\
\hline $\begin{array}{l}\text { Myocardial infarction } \\
\leq 30 \text { days previously }\end{array}$ & 16.9 & 19.2 & 0.45 \\
\hline $\begin{array}{l}\text { Myocardial infarction } \\
>30 \text { days previously }\end{array}$ & 19.5 & 21.0 & 0.82 \\
\hline Coronary angioplasty & 19.1 & 15.9 & 0.32 \\
\hline $\begin{array}{l}\text { Coronary-artery bypass } \\
\text { surgery }\end{array}$ & 3.5 & 3.4 & 1.00 \\
\hline \multicolumn{4}{|l|}{ Risk factors (\%) } \\
\hline Diabetes & 12.1 & 9.6 & 0.73 \\
\hline Hypercholesterolemia & 32.5 & 33.6 & 0.86 \\
\hline Hypertension & 39.3 & 34.5 & 0.47 \\
\hline Current smoking & 40.9 & 42.1 & 0.68 \\
\hline \multicolumn{4}{|l|}{$\begin{array}{l}\text { Medication before } \\
\text { enrollment (\%) }\end{array}$} \\
\hline Aspirin & 98.1 & 97.9 & 1.00 \\
\hline Intravenous heparin & 99.2 & 98.6 & 0.95 \\
\hline Intravenous nitrates & 98.8 & 99.7 & 1.00 \\
\hline Beta-blockers & 65.0 & 61.4 & 0.79 \\
\hline
\end{tabular}

* Plus-minus values are means \pm SD.

abciximab (5.5 percent, vs. 13.6 percent for those receiving placebo; $\mathrm{P}=0.03$ ).

\section{PATIENTS WITH ACUTE CHEST PAIN}

Of the 626 patients with acute chest pain, 308 had acute coronary syndromes (117 of whom had myocardial infarction without ST-segment elevation). Of the remaining patients stable angina was diagnosed in 91 , pulmonary embolism in 10 , congestive heart failure in 11, and myocarditis in 7 . No evidence of heart disease was found in 199. Soluble CD40 ligand levels were significantly higher in the 308 patients with acute coronary syndromes (mean, $4.53 \mu \mathrm{g}$ per liter; 95 percent confidence interval, 3.19 to 5.87 ) than in patients with stable angina (mean, $2.41 \mu \mathrm{g}$ per liter; 95 percent confidence interval, 1.99 to 3.52; $\mathrm{P}<0.001)$ and patients without evidence of heart disease (mean, $1.57 \mu$ g per liter; 95 percent confidence interval, 0.88 to 1.76 ; $\mathrm{P}<0.001$ ). The 97.5th percentile for the soluble CD40 ligand level in patients without evidence of heart disease was $4.7 \mu \mathrm{g}$ per liter, and the 99th percentile was $6.2 \mu \mathrm{g}$ per liter. Soluble 


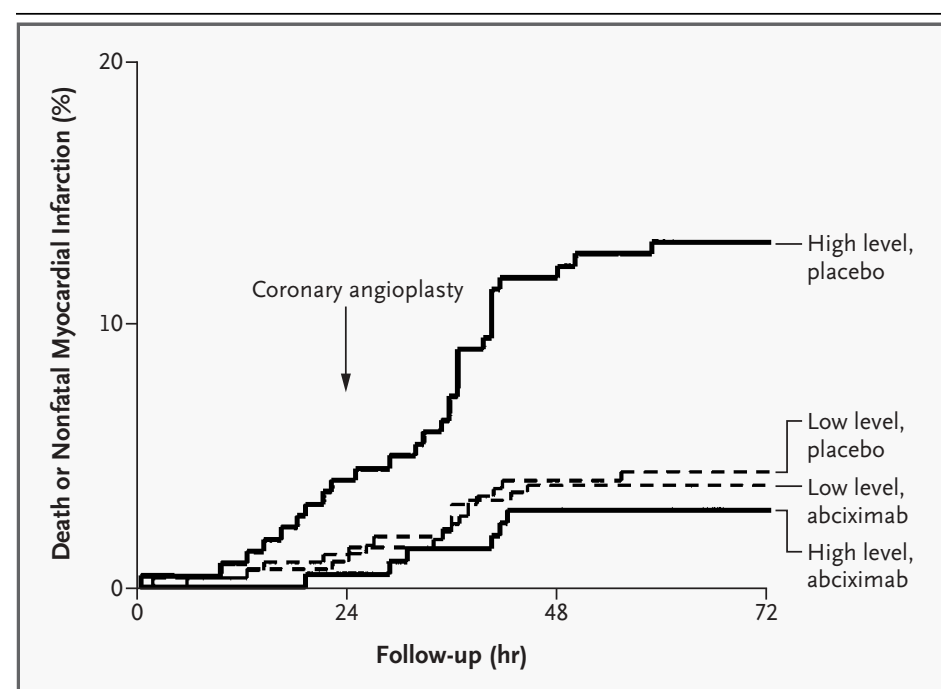

Figure 2. Kaplan-Meier Curves Showing the Cumulative Incidence of Death or Nonfatal Myocardial Infarction during 72 Hours of Follow-up, According to the Base-Line Level of Soluble CD40 Ligand in the Placebo Group (544 Patients) and the Abciximab Group (544 Patients).

High levels of soluble CD40 ligand were defined as levels greater than $5.0 \mu \mathrm{g}$ per liter, and low levels as $5.0 \mu \mathrm{g}$ per liter or less.

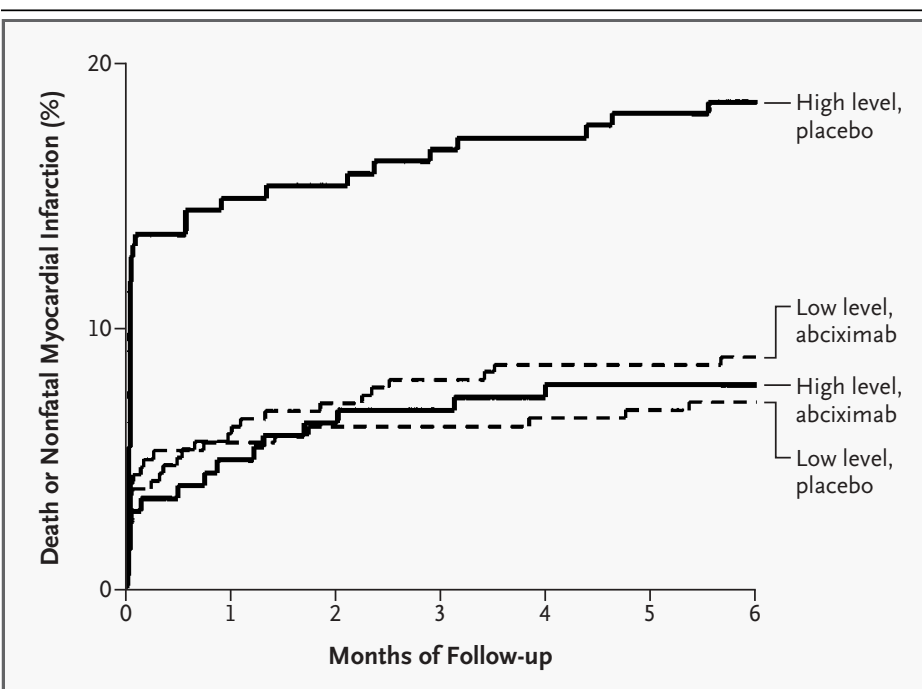

Figure 3. Kaplan-Meier Curves Showing the Cumulative Incidence of Death or Nonfatal Myocardial Infarction during Six Months of Follow-up, According to the Base-Line Level of Soluble CD40 Ligand in the Placebo Group (544 Patients) and the Abciximab Group (544 Patients).

High levels of soluble CD40 ligand were defined as levels greater than $5.0 \mu \mathrm{g}$ per liter, and low levels as $5.0 \mu \mathrm{g}$ per liter or less.
CD40 ligand levels did not correlate with markers of necrosis (troponin T levels), markers of inflammation (levels of C-reactive protein and tumor necrosis factor $\alpha$ ), or adhesion molecules (soluble intracellular adhesion molecule 1).

Among the 308 patients with acute coronary syndromes, 43.5 percent had soluble CD40 ligand levels above the 97.5 th-percentile upper reference limit. When the prespecified threshold value for soluble CD40 ligand of $5.0 \mu \mathrm{g}$ per liter was used, patients with elevated levels were at significantly higher risk for death or nonfatal myocardial infarction than those with lower levels (adjusted hazard ratio, 3.00; 95 percent confidence interval, 1.35 to 6.71 ; $\mathrm{P}=0.009$ ). Among the entire heterogeneous population of 626 patients with chest pain, the threshold value of $5.0 \mu \mathrm{g}$ per liter also reliably identified patients who were at highest risk for death or nonfatal myocardial infarction (adjusted hazard ratio, 6.65; 95 percent confidence interval, 3.18 to 13.89 ; $\mathrm{P}<0.001)$.

\section{ASSOCIATION OF SOLUBLE CD4O LIGAND LEVELS WITH PLATELET ACTIVATION}

In a subgroup of 161 patients with chest pain, we observed a strong correlation between platelet activation, as evidenced by the percentage of monocytes that were aggregated with platelets (monocyte-platelet aggregates), and soluble CD40 ligand levels $(r=0.75, P<0.001)$ (Fig. 5). Similar results were obtained for P-selectin expression on platelets ( $\mathrm{P}<0.001$; data not shown). Patients were divided into three roughly equal groups according to their measured levels of soluble CD40 ligand: 55 with levels below $2.5 \mu \mathrm{g}$ per liter, 50 with levels of 2.5 to $4.5 \mu \mathrm{g}$ per liter, and 56 with levels above $4.5 \mu \mathrm{g}$ per liter. For patients in the group with the lowest levels, the mean percentage of monocyte-platelet aggregates was $11.3 \pm 6.1$ percent. For those in the other two groups, platelet activation was significantly higher, with monocyte-platelet aggregates of $22.3 \pm 8.9$ percent $(\mathrm{P}<0.001)$ and $34.1 \pm 15.6$ percent $(\mathrm{P}<0.001)$, respectively.

\section{DISCUSSION}

The present study demonstrates that soluble CD40 ligand is a powerful biochemical marker of inflammatory thrombotic activity in patients with acute coronary syndromes. Elevated levels of soluble CD40 
ligand reliably identify the subgroup of patients with acute coronary syndromes who are at highest risk for cardiac events and who receive substantial benefit from treatment with the glycoprotein IIb/IIIa receptor antagonist abciximab. Thus, soluble CD40 ligand not only contributes importantly to the pathophysiology of acute coronary syndromes but also represents a reliable and powerful clinical marker for use in identifying patients with high-risk atherosclerotic lesions, coronary thrombosis, or both. ${ }^{15,22}$

Soluble CD40 ligand was a powerful prognostic marker that provided information beyond the evidence provided by troponin $\mathrm{T}$, the inflammatory marker C-reactive protein, tumor necrosis factor $\alpha$, and the soluble intracellular adhesion molecule 1. In a multivariate Cox regression model, troponin T, C-reactive protein, and soluble CD40 ligand provided independent and incremental prognostic information (Table 2). Troponins are markers of myocardial necrosis; they are not actively involved in the pathophysiology of acute coronary syndromes but, rather, are surrogate markers for the formation of fragile thrombi. ${ }^{2-4}$ Postmortem studies in patients with acute coronary syndromes identified erosion or rupture of the fibrous cap of the atherosclerotic plaque, leading to platelet activation, as the underlying pathophysiological feature..$^{5,6,23-25}$ Coronary arterial thromboembolism, with altered microvascular perfusion and necrosis, is an integral part of acute coronary syndromes. ${ }^{3,4}$ Accordingly, sensitive markers for the detection of minor myocardial injury, notably troponins, serve as surrogate markers for arterial thromboembolism originating from an active thrombotic process in the culprit lesion.

In contrast, soluble CD40 ligand may be directly involved in multiple ways in the pathophysiology of acute coronary syndromes. Recent evidence suggests that soluble CD40 ligand contributes importantly to the progression of atherosclerosis and, consequently, to the destabilization of atherosclerotic plaques ${ }^{5,6}$ by inducing the expression of cytokines, chemokines, growth factors, matrix metalloproteinases, and procoagulant factors in a variety of atheroma-associated cell types. , $^{7,11,12,26,27}$ Activated platelets produce and release large amounts of soluble CD40 ligand. ${ }^{11}$ A recent study demonstrated that cardiopulmonary bypass causes an increase in the plasma level of soluble CD40 ligand, with a corresponding decrease in platelet CD40 lig-
Table 2. Hazard Ratios for Death or Nonfatal Myocardial Infarction during Six Months of Follow-up among Patients Receiving Placebo.*

\begin{tabular}{|lcc|}
\hline Variable & Hazard Ratio (95\% Cl) & P Value \\
Male sex & $0.91(0.68-1.39)$ & 0.16 \\
Age $>65$ yr & $1.36(0.91-1.82)$ & 0.34 \\
Diabetes mellitus & $1.22(0.83-1.49)$ & 0.61 \\
Hypercholesterolemia & $0.90(0.68-1.13)$ & 0.59 \\
Hypertension & $1.00(0.89-1.04)$ & 1.00 \\
History of coronary heart disease & $0.86(0.65-1.19)$ & 0.72 \\
ST-segment depression & $1.04(0.76-1.54)$ & 0.74 \\
Troponin T >0.1 $\mu \mathrm{g}$ per liter & $2.94(1.75-7.26)$ & $<0.001$ \\
C-reactive protein $>10.0 \mathrm{mg}$ per liter & $2.03(1.11-3.59)$ & 0.02 \\
Soluble CD40 ligand $>5.0 \mu \mathrm{g}$ per liter & $2.71(1.51-5.35)$ & 0.001 \\
\hline
\end{tabular}

* The hazard ratios are derived from the multivariate Cox proportional-hazards regression model. $\mathrm{Cl}$ denotes confidence interval.

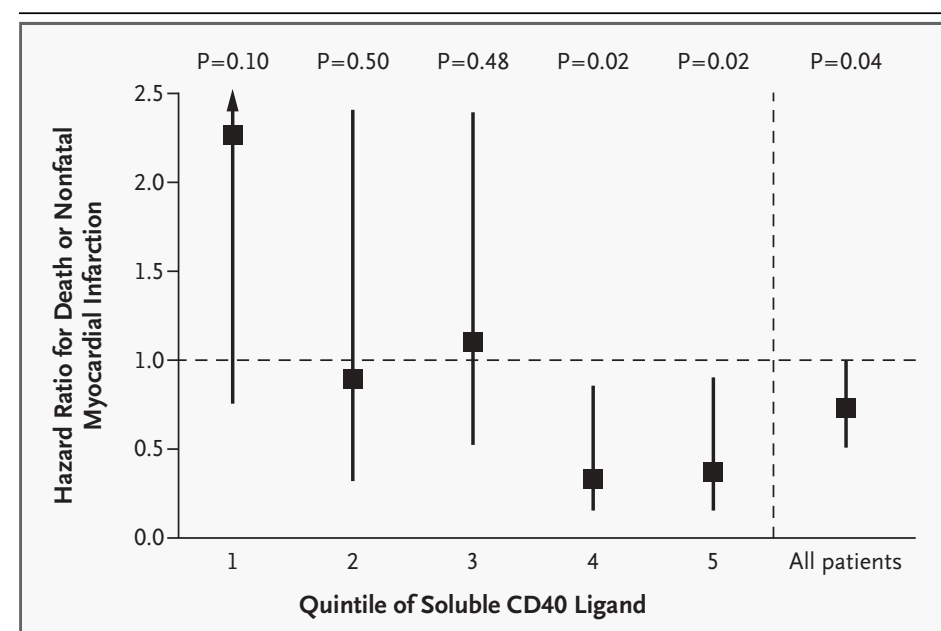

Figure 4. Adjusted Hazard Ratios (Solid Squares) and 95 Percent Confidence Intervals (Vertical Lines) Associated with Treatment with Abciximab, as Compared with Placebo, According to Quintiles of Soluble CD40 Ligand.

The levels of soluble CD40 ligand were as follows: first quintile, $<1.93 \mu \mathrm{g}$ per liter; second quintile, 1.93 to $3.50 \mu \mathrm{g}$ per liter; third quintile, 3.51 to $5.00 \mu \mathrm{g}$ per liter; fourth quintile, 5.01 to $6.30 \mu \mathrm{g}$ per liter; and fifth quintile, more than $6.30 \mu \mathrm{g}$ per liter. The effect of treatment with abciximab was measured as the reduction in the rate of death or nonfatal myocardial infarction during six months of follow-up. Hazard ratios below 1.0 indicate a benefit of treatment with abciximab as compared with placebo. Hazard ratios have been adjusted for base-line characteristics. 


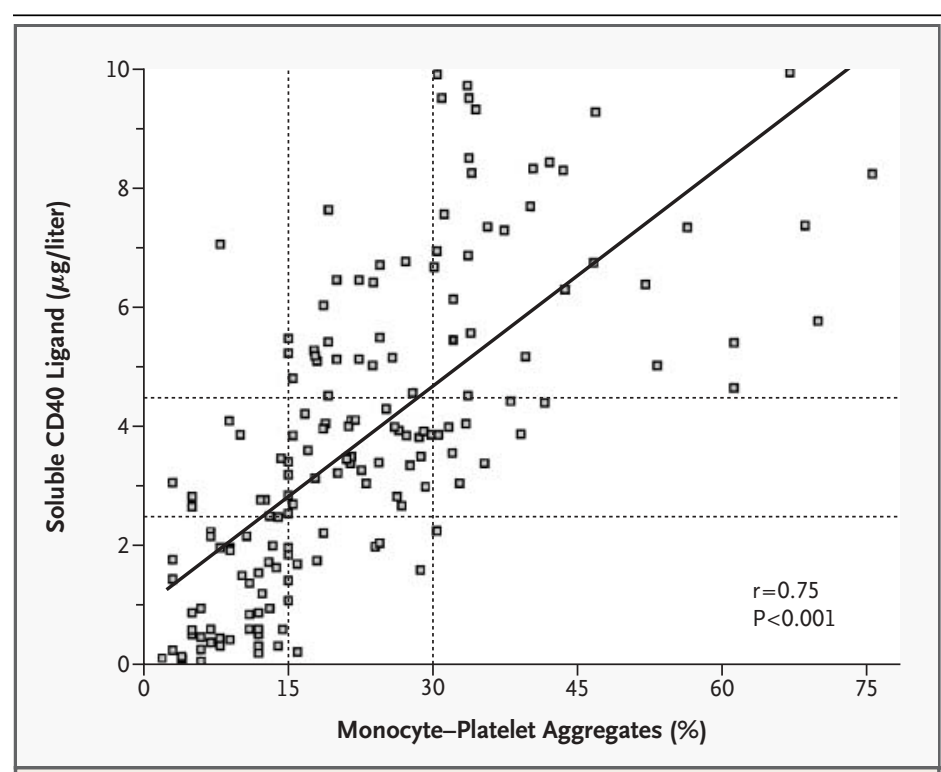

Figure 5. Correlation between the Level of Soluble CD40 Ligand and Platelet Activation in 161 Patients with Chest Pain.

Platelet activation is expressed as the percentage of monocytes that were aggregated with platelets (monocyte-platelet aggregates). Dotted lines indicate the classification of patients into three roughly equal groups according to the degree of platelet activation ( $<15$ percent, 15 to 30 percent, and $>30$ percent) and according to soluble CD40 ligand levels ( $<2.5 \mu \mathrm{g}$ per liter, 2.5 to $4.5 \mu \mathrm{g}$ per liter, and $>4.5 \mu \mathrm{g}$ per liter).

and content, suggesting that soluble CD40 ligand is derived primarily from platelets and may contribute to the thrombotic complications associated with cardiopulmonary bypass. ${ }^{28}$ Soluble CD40 ligand levels correlate positively with plasma levels of soluble P-selectin and urinary levels of 11-dehydrothromboxane $\mathrm{B}_{2} \cdot{ }^{29}$ In addition, experimental studies demonstrate that CD40 ligand is required for arterial thrombus stabilization. ${ }^{15}$

Our results provide further evidence that soluble CD40 ligand is a marker of inflammatory thrombotic activity. Platelet activation, as determined by flow cytometry in patients with acute coronary syndromes, correlated closely with soluble CD40 ligand levels (Fig. 5). These findings are supported by the fact that inhibition of glycoprotein IIb/IIIa receptors by abciximab abrogated the increased risk in patients with acute coronary syndromes and elevated levels of soluble CD40 ligand. Thus, whereas positivity for troponins may indicate the propensity of the thrombus to embolize, leading to myocardial necrosis, elevated soluble CD40 ligand levels in patients with acute coronary syndromes appear to re- flect the inflammatory thrombotic activity of the culprit lesion in recruiting and activating platelets.

In a previous subgroup analysis of data from the CAPTURE trial, we demonstrated that additional treatment with the glycoprotein IIb/IIIa receptor antagonist abciximab reduced the elevated risk of death or nonfatal myocardial infarction among troponin-positive patients to the risk level among troponin-negative patients. ${ }^{21}$ Such patients represent about one third of those with acute coronary syndromes. ${ }^{1,30-33}$ Similar findings for troponin $\mathrm{T}$ and troponin I have emerged from other trials, ${ }^{34-36}$ and measurement of troponins was subsequently incorporated into the new guidelines as part of risk stratification of patients with acute coronary syndromes. ${ }^{37,38}$ Here, we demonstrate that a pronounced benefit of antiplatelet therapy is also evident in patients with elevated levels of soluble CD40 ligand. Our findings suggest that patients with acute coronary syndromes who have elevated levels of soluble CD40 ligand are effectively protected from adverse cardiac events by the glycoprotein IIb/IIIa receptor antagonist abciximab (Fig. 2 and 3).

Troponin T and soluble CD40 ligand have independent predictive value with respect to both the risk of ischemic events and the benefit of glycoprotein IIb/IIIa receptor inhibition by abciximab. Patients without evidence of myocardial injury (i.e., with no elevation of troponin levels), but with increased soluble CD40 ligand levels, were at increased risk for cardiovascular events and derived substantial benefit from treatment with the glycoprotein IIb/IIIa inhibitor abciximab. Accordingly, patients at high risk for coronary thrombosis, as evidenced by elevation of either soluble CD40 ligand or troponin T levels, who represented 54 percent of the patients enrolled in the CAPTURE trial, derived a marked benefit from abciximab treatment, as compared with the placebo group, with an adjusted hazard ratio for death or myocardial infarction of 0.38 (95 percent confidence interval, 0.21 to 0.72 ; $\mathrm{P}<0.001$ ) (data not shown). Thus, the measurement of both troponins and soluble CD40 ligand, which are separate but interacting components of the underlying pathophysiological process in patients with acute coronary syndromes, provides important insights into disease activity, cardiac risk, and the effect of inhibition of glycoprotein IIb/IIIa with abciximab that are superior to those obtained with the use of a single marker. 
Supported by a research grant from the University of Frankfurt, Frankfurt, Germany.

Dr. Heeschen reports having received lecture fees from Merck, Roche Diagnostics, and Abbott Laboratories.
We are indebted to Sylvia Rhiel and Christiane Mildner-Rihm for their expert technical assistance. A list of the principal investigators and committee members of the CAPTURE Study Investigators has been published previously. ${ }^{18}$
REFERENCES

1. Hamm CW, Braunwald E. A classification of unstable angina revisited. Circulation 2000;102:118-22.

2. Lindahl B, Diderholm E, Lagerqvist B Venge P, Wallentin L. Mechanisms behind the prognostic value of troponin $\mathrm{T}$ in unstable coronary artery disease: a FRISC II substudy. J Am Coll Cardiol 2001;38:979-86.

3. Heeschen C, van Den Brand MJ, Hamm $\mathrm{CW}$, Simoons ML. Angiographic findings in patients with refractory unstable angina according to troponin T status. Circulation 1999;100:1509-14.

4. Benamer H, Steg PG, Benessiano J, et al Elevated cardiac troponin I predicts a high-risk angiographic anatomy of the culprit lesion in unstable angina. Am Heart J 1999;137: 815-20

5. Mach F, Schonbeck U, Sukhova GK Atkinson E, Libby P. Reduction of atherosclerosis in mice by inhibition of CD40 signalling. Nature 1998;394:200-3.

6. Lutgens E, Gorelik L, Daemen MJ, et al. Requirement for CD 154 in the progression of atherosclerosis. Nat Med 1999;5:1313-6. 7. Schonbeck U, Libby P. The CD40/CD154 receptor/ligand dyad. Cell Mol Life Sci 2001; 58:4-43.

8. Henn V, SlupskyJR, Grafe M, et al. CD40 ligand on activated platelets triggers an inflammatory reaction of endothelial cells Nature 1998;391:591-4

9. GrafD, Muller S, Korthauer U, van Kooten C, Weise C, Kroczek RA. A soluble form of TRAP (CD40 ligand) is rapidly released after T cell activation. Eur J Immunol 1995;25: 1749-54.

10. LeeY, Lee WH, Lee SC, et al. CD40L activation in circulating platelets in patients with acute coronary syndrome. Cardiology 1999 92:11-6.

11. Henn V, Steinbach S, Buchner K, Presek P, Kroczek RA. The inflammatory action of CD40 ligand (CD154) expressed on activated human platelets is temporally limited by coexpressed CD40. Blood 2001;98:1047-54. 12. Mach F, Schonbeck U, BonnefoyJY, Pobe JS, Libby P. Activation of monocyte/macrophage functions related to acute atheroma complication by ligation of CD40: induction of collagenase, stromelysin, and tissue factor. Circulation 1997;96:396-9.

13. Urbich C, Mallat Z, Tedgui A, Clauss $M$, Zeiher AM, Dimmeler S. Upregulation of TRAF- 3 by shear stress blocks CD40-mediated endothelial activation. J Clin Invest 2001; 108:1451-8.

14. Scarborough RM, Naughton MA, Teng $\mathrm{W}$, et al. Design of potent and specific integrin antagonists: peptide antagonists with high specificity for glycoprotein IIb-IIIa. J Biol Chem 1993;268:1066-73.
15. Andre P, Prasad KS, Denis CV, et al. CD40L stabilizes arterial thrombi by a beta 3 integrin-dependent mechanism. Nat Med 2002;8:247-52.

16. Schonbeck U, Varo N, Libby P, Buring J, Ridker PM. Soluble CD40L and cardiovascular risk in women. Circulation 2001;104: 2266-8.

17. Aukrust P, Muller F, Ueland T, et al. Enhanced levels of soluble and membranebound CD40 ligand in patients with unstable angina: possible reflection of $\mathrm{T}$ lymphocyte and platelet involvement in the pathogenesis of acute coronary syndromes. Circulation 1999;100:614-20.

18. Randomised placebo-controlled trial of abciximab before and during coronary intervention in refractory unstable angina: the CAPTURE Study. Lancet 1997;349:1429-35. [Erratum, Lancet 1997;350:744.]

19. Michelson AD, Barnard MR, Kruege LA, Valeri CR, Furman MI. Circulating monocyte-platelet aggregates are a more sensitive marker of in vivo platelet activation than platelet surface P-selectin: studies in baboons, human coronary intervention, and human acute myocardial infarction. Circulation 2001; 104:1533-7.

20. Cox DR. Regression models and lifetables. J R Stat Soc [B] 1972;34:187-220. 21. Hamm CW, Heeschen C, Goldmann B, et al. Benefit of abciximab in patients with refractory unstable angina in relation to serum troponin T levels. N Engl J Med 1999; 340:1623-9. [Erratum, N Engl J Med 1999, 341:548.]

22. Andre P, Nannizzi-Alaimo L, Prasad SK Phillips DR. Platelet-derived CD40L: the switch-hitting player of cardiovascular disease. Circulation 2002;106:896-9.

23. Farb A, Burke AP, Tang AL, et al. Coronary plaque erosion without rupture into a lipid core: a frequent cause of coronary thrombosis in sudden coronary death. Circulation 1996;93:1354-63.

24. Davies MJ, Thomas AC. Plaque fissur ing - the cause of acute myocardial infarction, sudden ischaemic death, and crescendo angina. Br Heart J 1985;53:363-73.

25. Davies MJ. The composition of coronary-artery plaques. N Engl J Med 1997;336: 1312-4.

26. Miller DL, Yaron R, Yellin MJ. CD40LCD40 interactions regulate endothelial cel surface tissue factor and thrombomodulin expression. J Leukoc Biol 1998;63:373-9.

27. Kotowicz K, Dixon GL, Klein NJ, Peter MJ, Callard RE. Biological function of CD40 on human endothelial cells: costimulation with CD40 ligand and interleukin-4 selectively induces expression of vascular cell adhesion molecule- 1 and P-selectin result- ing in preferential adhesion of lymphocytes. Immunology 2000;100:441-8.

28. Nannizzi-Alaimo L, Rubenstein $\mathrm{MH}$, Alves VL, Leong GY, Phillips DR, Gold HK.

Cardiopulmonary bypass induces release of soluble CD40 ligand. Circulation 2002;105: 2849-54

29. Cipollone F, Mezzetti A, Porreca E, et al. Association between enhanced soluble CD40 and prothrombotic state in hypercholesterolemia: effects of statin therapy. Circulation 2002;106:399-402.

30. Antman EM, Tanasijevic MJ, Thompson $\mathrm{B}$, et al. Cardiac-specific troponin I levels to predict the risk of mortality in patients with acute coronary syndromes. N Engl J Med 1996 335:1342-9.

31. Ohman EM, Armstrong PW, Christenson $\mathrm{RH}$, et al. Cardiac troponin $\mathrm{T}$ levels for risk stratification in acute myocardial ischemia. N Engl J Med 1996;335:1333-41.

32. Hamm CW, Ravkilde J, Gerhardt W, et al. The prognostic value of serum troponin $\mathrm{T}$ in unstable angina. N Engl J Med 1992;327: 146-50.

33. Hamm CW, Goldmann BU, Heeschen C, Kreymann G, BergerJ, Meinertz T. Emergency room triage of patients with acute chest pain by means of rapid testing for cardiac troponin T or troponin I. N Engl J Med 1997;337: 1648-53.

34. Newby LK, Ohman EM, Christenson RH, et al. Benefit of glycoprotein IIb/IIIa inhibition in patients with acute coronary syndromes and troponin T-positive status: the paragon-B troponin T substudy. Circulation 2001;103:2891-6.

35. Januzzi JL, Chae CU, Sabatine MS, Jang IK. Elevation in serum troponin I predicts the benefit of tirofiban. J Thromb Thrombolysis 2001;11:211-5.

36. Heeschen C, Hamm CW, Goldmann B, Deu A, Langenbrink L, White HD. Troponin concentrations for stratification of patients with acute coronary syndromes in relation to therapeutic efficacy of tirofiban. Lancet 1999;354:1757-62.

37. Hamm CW, Bertrand M, Braunwald E. Acute coronary syndrome without ST elevation: implementation of new guidelines. Lancet 2001;358:1533-8.

38. Braunwald E, Maseri A, Armstrong PW, et al. Rationale and clinical evidence for the use of GP IIb/IIIa inhibitors in acute coronary syndromes. Eur Heart J 1998;19:Supp D:D22-D30.

Copyright (c) 2003 Massachusetts Medical Society. 